\title{
Evidence-based medicine
}

\section{An improved format for journal clubs}

\author{
Simon Gilbody
}

\begin{abstract}
Evidence-based medicine is an approach to clinical training and proctice that is increasing in populatty. When introduced into the joumal club format, it provides an opportunity to integrate real clinical problems with crtilical evaluation of the poychiatilic resecarch literature. The principles of evidence-based medicine and the practicalities of tis introduction into the joumal club format are described.
\end{abstract}

"Master evidence-based medicine and transform a journal club from a passtve summary of assigned journals into an active enquiry in which problems arising from patient care are used to direct searches and appraisals to keep practice up to date". Rosenberg \& Donald, 1995

\section{Why a need for change?}

The College requires that all training schemes incorporate attendance at a weekly meeting where psychiatric research literature is presented and discussed. The quality of these journal clubs varies widely. The source of the papers is frequently the College reading list, and while these papers are usually important, they may seem detached from everyday clinical problems. All too often trainees labour through the papers page by page without adequate guidance on how to appraise the article critically or present it in a lively way. Consequently the discussion tends to be passive acceptance of the facts, rather than critical evaluation of the study's design, conduct, analysis and its relevance to clinical practice. Unfortunately, trainees are often reluctant to suggest changes in format; this article suggests one new approach.

\section{An evidence-based approach}

Evidence-based medicine is a concept which is beginning to influence all spheres of medicine and which has recently seen the publication of its own major journal (Haynes \& Sackett, 1995). It has been defined as "the process of systematically finding, appraising and using contemporaneous research" (Rosenberg \& Donald, 1995). It takes as its starting point everyday clinical problems.
When systematically used, it improves the quality of clinical decisions and effective use of the medical literature among cliniclans (Shin et al, 1993). The problem based approach has been incorporated into some undergraduate medical curricula and many of its features can readily become part of postgraduate psychlatric courses (Owens et al, 1995).

If there is uncertainty about some aspect of clinical management (diagnosis, prognosis or management), four steps are proposed (Rosenberg \& Donald, 1995):

(1) formulate a clear clinical question in patient management

(2) search the literature for relevant clinical articles

(3) evaluate (critically appraise) evidence for effectiveness and usefulness

(4) implement useful findings in clinical practice

The first three of these stages are ideally suited to the journal club format.

\section{Formulation of a clinical question}

Much of our established practice is based on recetved wisdom or idiosyncratic opinion. Trainees, who move frequently between posts, know this. They have no difficulty in coming up with clinically important questions from their current caseload. By setting out to examine whether we have answers to these questions, evidence-based medicine can be a central aspect of training rather than a sterile academic activity. The following list presents some clinical questions generated by trainees from clinical problems encountered in the space of the preceding week.

(1) Should benzodiazepines be prescribed to all patients with alcohol problems during detoxification or can they be started only if withdrawal symptoms develop?

(2) How good are brief cognittve rating scales (such as the Hodkinson scale) in detecting cognitive impairment, and how do they compare with longer diagnostic instruments? 
(3) How long should antidepressants be continued following successful treatment of a first depresstve episode?

(4) What proportion of children with depresstve disorder respond to antidepressant medication?

(5) What is the long-term prognosis for patients presenting with a first episode of mania, and what is the value of mood stabilising medication with these patients?

\section{Searching the literature}

Searching libraries and computerised databases for unblased evidence develops skills which will become increasingly important in training and for continuing professional development (Lindberg et al, 1993). Before long, for example, those who want to keep up with the medical literature will need to understand systematic reviewing and the pitfalls of uncritical and selective searches.

\section{Critically evaluating the evidence}

In examining the weight of evidence, journal clubs of the kind proposed will emphasise that some study designs are less prone to blas than others. For example, sources of evidence can be ranked (adapted from Sheldon et al, 1993):

(1) well designed randomised controlled trials

(2) non-randomised controlled trials

(3) cohort studies

(4) case-control studies

(5) large differences from comparisons between times and/or places with or without intervention

(6) opinions of experts based on experience, descriptive studies, and reports of expert committees.

Within each of these types of study, there are readily avallable guides to whether the findings can be believed. The textbook by Sackett et al (1992) and the series of Journal of the American Medical Association articles known as Users Guides (see Oxman et al, 1993) provide clear and concise criteria for randomised controlled trials, case-control studies and so on. Similar guidelines are also set out in the statement of purposes and procedures of the new journal Evidence-Based Medicine (Haynes \& Sackett, 1995). Examples of the primary criteria for judging the validity of research evidence are given in Box 1 .

\section{The practicalities and potential problems of an evidence-based journal club}

An effective evidence-based journal club requires adequate resources: access to a CD-ROM
Box 1. Readers guides for selecting articles that are most likely to provide valid results (adapted from Oxman et al, 1993)

Therapy

- Was the assignment of patients to treatments randomised?

- Were all the patients who entered the trial property accounted for and attributed at its conclusion?

\section{Diagnosis}

- Was there an independent, blind comparison with a reference standard?

- Did the patient sample include an approprlate spectrum of the sort of patients to whom the diagnostic test will be applied in clinical practice?

Harm

- Were there clearly identified comparison groups that were similar with respect to important determinants of outcome (other than the one of interest)?

- Were outcomes and exposures measured in the same way in the groups being compared?

Prognosis

- Was there a representative patient sample at a well-defined point in the course of the disease?

- Was follow-up sufficiently long and complete?

literature database, a library stocked with psychiatric journals, and access to a library with a wider range of journals. Adopting an evidencebased format could help to provide the impetus to purchase a (now relatively inexpensive) CD-ROM system for a hospital library. In spite of their technological advantage, electronic literature databases do not give a complete source of references. They do, however, offer the best starting point for any literature search. Conducting literature searches on computerised databases can seem daunting to some trainees, but the skdlls are easily learnt (Lingberg et al, 1993) and can be introduced during the initial sessions.

The time commitment required in preparing a presentation need be no greater than that required for a conventional journal presentation. Effective literature searches can be completed in less than 10 minutes once the key skills have been attained. The presentation of the best available evidence should fill no more than two 'overheads', and should reflect the style of a 'structured abstract' (background, design, method, results and main clinical messages). Succinct communication of research evidence in this way helps to improve presentational skills of trainees. The actual appraisal of the evidence should take 
place within the meeting and should involve all participants.

The change in the format requires a degree of commitment and enthusiasm on the part of both the trainees and clinical tutors. The format is best introduced at the start of a six month clinical attachment. Such a change should take place by the agreement of trainees, rather than being imposed upon unwilling participants. Interested consultants and clinical tutors could initiate the process by presenting a sample question, together with a worked example of a literature search and critical appraisal. Key papers (e.g. Lindberg et al, 1993; Oxman et al, 1993; Rosenberg \& Donald, 1995) can be set as initial reading material for participants. Once established, the journal club should become selfperpetuating: questions are developed by trainees on a weekly basis to be discussed the next week.

It is likely that the process of critical evaluation will reveal that the research evidence either does not exist or is not sufficiently valid to provide answers to many clinical questions. Clinical tutors can help the process in the initial stages by encouraging questions to be set which will yield some research evidence.

\section{Will the journal club be successful?}

Trainees prefer to generate their own clinical questions and to discuss papers which have an obvious relevance to their day to day work. Only in this way can postgraduate medical education become integrated into clinical practice. The knowledge gained is much more up-to-date than that derived from textbooks. More importantly, skills are developed which improve critical evaluation and evidence-based practice. Learning becomes problem-based, self-directed and clinically relevant. As a bonus, critical study of the research literature can expose what we do not know and so can help trainees to generate research questions, and the methods they might use to answer them in research of their own.

\section{Acknowledgement}

I would like to thank Dr David Owens for his useful comments on an earlier draft of this paper.

\section{References}

HAYNES, R. B. \& SACKETT, D. L. (1995) Purpose and procedure. Evidence-Based Medictne, 1. 2.

LINDBERG, D. A. B., STEGEL, E. R., RAPP, B. A., et al (1993) Use of MEDLINE by physicians for clinical problem solving. Journal of the American Medical Association. 269. 3124-3129.

OWENS, D., HOUSE, A. \& WORRALL, A. (1995) A strategy to improve standards in education and supervision. Psychiatric Bulletin, 19, 337-340.

OXMAN, A. D., SACKETT, D. L. \& GUYATT, G. H. for the Evidence Based Medicine Working Group (1993) Users guides to the medical literature I: How to get started. Joumal of the American Medical Association, 270. 2093-2095.

ROSENBERG, W. \& DONALD, A. (1995) Evidence-based medicine: an approach to clinical problem solving. British Medical Journal, 310, 1122-1126.

SACKETT, D. L.. HAYNES, R. B., GUYATT, G. H., et al (1992) Clinical Epidemiology: A Basic Science for Clinical Medicine (second edition). Boston: Little, Brown and Co.

SHELDON, T. A., SONG, F. \& DAVEY-SMmH G. A. (1993) Critical appraisal of the medical literature: how to assess whether health care interventions do more good than harm. In Purchasing and Providing Cost Effectwe Health Care (eds M. F. Drummond \& A. Maynard). Edinburgh: Churchill Livingstone.

SHIN, J. H., HAYNES, R. B. \& JoHnson, M. E. (1993) The effect of problem based, self-directed undergraduate education on life-long learning. Canadian Medical Association Journal, 148, 969-976.

Simon Gilbody, MRC Training Fellow in Health Services Research, NHS Centre for Reviews and Dissemination, Uniwersity of York, York YO1 5DD, E-mail: RevDis@York.Ac.UK 